\title{
Modelling the recovery of surface water chemistry and the ecological implications in the British uplands
}

\author{
R.C. Helliwell ${ }^{1}$, A. Jenkins ${ }^{2}$, R.C. Ferrier ${ }^{1}$ and B.J. Cosby ${ }^{3}$ \\ ${ }^{1}$ Macaulay Institute, Craigiebuckler, Aberdeen, AB15 8QH, UK \\ ${ }^{2}$ Centre for Ecology and Hydrology, Wallingford, Oxon OX10 8BB, UK \\ ${ }^{3}$ Department of Environmental Sciences, University of Virginia, Charlottesville, VA22901, USA \\ Email for corresponding author: r.helliwell@macaulay.ac.uk
}

\begin{abstract}
The MAGIC (Model of Acidification of Groundwaters in Catchments) model has been calibrated to three acid sensitive regions in the UK: Galloway, the South Pennines and Wales. These calibrations use the best available data for surface water, soil and deposition, from several UK data bases and regional sampling programmes. The model is capable of reproducing observed base cation and acid anion concentrations as reflected by a close match between observed and simulated acid neutralising capacity (ANC). Predictions to 2016 under currently agreed emission reductions, the Gothenburg Protocol, show that ANC greater than zero will be achieved at $100 \%, 86 \%$ and $100 \%$ of sites in Galloway, the Pennines and Wales, respectively. This indicates the potential for biological recovery and a return to 'good status' although chemical conditions remain some way from simulated pre-acidification conditions. In the longer term, beyond 2036 (20 years after compliance with the Gothenburg protocol), the model indicates that increased $\mathrm{N}$ leakage to surface waters may cause deterioration in the chemical status.
\end{abstract}

Keywords: recovery, acidification, modelling, upland UK, ecology

\section{Introduction}

In upland areas of the UK generally, pristine water prevails but, since the middle of the last century, there is clear evidence of a shift towards more acidic conditions (Battarbee et al., 1988). This problem of surface water acidification is linked to the emission of acidic oxides of sulphur (S) and nitrogen $(\mathrm{N})$ mainly from the burning of fossil fuels as well as reduced forms of $\mathrm{N}$ from agricultural production (NEGTAP, 2001). The main concern over increased acidity lies in its impact on aquatic biology; it has been found, to affect fish adversely (Lien et al., 1996; Juggins,2001; McCartney et al., 2003), invertebrates (Raddum and Skjelkvale, 2001; Raddum and Fjellheim, 2003) and phytoplankton (Findlay, 2003). Further, impacts on bird populations have also been inferred (Ormerod and Tyler, 1989).

Since the peak of acidic emissions in the UK in the late 1970s, a substantial decline, particularly in S emission, has led to recovery towards less acid conditions in many areas. This is well documented in long term surface water chemistry data in the UK (Evans et al., 2001; NEGTAP 2001). This decline in S emission is a direct result of national and international policy in the form of the Convention of Long Range Transboundary Air Pollution and more recently under direct EU legislation. The former has been responsible for establishing four emission Protocols, the last of which being the Gothenburg Protocol signed in 1999 but not yet ratified, and the latter has established the Large Combustion Plants Directive and is currently implementing the National Emissions Ceilings Directive within the framework of the Clean Air for Europe programme.

The desire to remedy the problem of surface water acidification per se has now been bolstered by a further policy driver, the EU Water Framework Directive. This legislation demands that all surface waters should be managed to achieve 'good ecological' status by 2016. Good ecological status is defined with respect to a pristine reference condition. Since the ecological status depends on biological status in terms of fish, macrophytes and phytoplankton, all of which are affected by acidification, it 
is clear that achieving the aims of the WFD depends on the success of the existing emission reduction policies.

The Multi-Pollutant, Multi-Effect (Gothenburg) Protocol was established on the basis of the critical loads concept (Nilsson and Grennfelt, 1988) to reduce the level by which $\mathrm{S}$ and $\mathrm{N}$ depositions exceed critical loads. The critical load concept implies that once the deposition is reduced to a level below the critical load then the ecosystem is protected. However, this assumes no timescale in the recovery process and the recovery in chemical conditions and biological status may take many decades following the achievement of the critical load. Dynamic models can quantify the timescale of the chemical recovery in response to reduced deposition and so have a clear role in assessing the benefits of the existing legislation and its implications for implementing the Water Framework Directive.

This study describes the application of MAGIC (Model of Acidification of Groundwater In Catchments; Cosby et al., 1985a,b, 2001) to three areas with acid sensitive waters in the UK, with the aim of assessing their chemical, biological and ecological status in 2016. Model simulations are also run further into the future, to 2036, to address the longer term responses with respect to uncertainties relating to the description of terrestrial $\mathrm{N}$ dynamics within the model.

\section{Methods}

\section{THE STUDY REGIONS}

The three regions were selected for this study on the basis of their sensitivity to acidification as indicated by their relatively low critical load (NEGTAP, 2001), their relatively high level of $\mathrm{S}$ and $\mathrm{N}$ deposition (Table 1) as indicated by their current critical load exceedance (NEGTAP, 2001) and availability of appropriate surface water and soil chemistry data. The sensitivity of surface water to acidic deposition in these regions is due mainly to the characteristics of their underlying geologies. The granitic bedrock characteristic of the higher elevations in Galloway in south-west Scotland is resistant to weathering and so provides a relatively low supply of base cations to neutralise acidic deposition (Ferrier et al., 2001). In the Welsh region, rocks of Cambrian, Ordovician and Silurian age tend to be base poor and so, despite being less resistant to weathering, also provide a small flux of base cations to buffer acidity (Sefton and Jenkins, 1998). This is similarly true in the Pennines where Millstone Grits of Carboniferous age are extremely low in base cations (Evans et al., 2000).

The soils in all regions are predominantly organic in nature with peats, peaty gleys and stagnopodzol. In Galloway,

Table 1. Site characteristics for 3 upland regions (Number of sites shown in brackets, Scottish soil classification in italics)

\begin{tabular}{|c|c|c|c|}
\hline & Galloway & Wales & Pennines \\
\hline Number of sites & 54 & 95 & 62 \\
\hline Geology & $\begin{array}{l}\text { Granite } \\
\text { Greywackes }\end{array}$ & $\begin{array}{l}\text { Acid-igneous and } \\
\text { meta-sedimentary } \\
\text { bedrock }\end{array}$ & $\begin{array}{l}\text { Millstone Grits } \\
\text { Coal measures }\end{array}$ \\
\hline Soils & $\begin{array}{l}\text { Peat } \\
\text { Stagnohumic gley(Peaty gley) } \\
\text { Ferri-humic cryptopodzol } \\
\text { (Sub-alpine soil) } \\
\text { Brown earth }\end{array}$ & $\begin{array}{l}\text { Peaty gley } \\
\text { Stagnopodzol } \\
\text { Stagnohumic gley } \\
\text { Brown podzol } \\
\text { Ranker }\end{array}$ & $\begin{array}{l}\text { Blanket peat } \\
\text { Iron pan stagnopodzol } \\
\text { Stagnohumic gley } \\
\text { Brown earth }\end{array}$ \\
\hline Land use & $\begin{array}{l}\text { Moorland (23) } \\
\text { Forest (34) }\end{array}$ & $\begin{array}{l}\text { Moorland (39) } \\
\text { Forest (56) }\end{array}$ & $\begin{array}{l}\text { Moorland (56) } \\
\text { Forest (6) }\end{array}$ \\
\hline Deposition & $\begin{array}{l}32 \mathrm{~kg} / \mathrm{Sha} / \mathrm{yr}^{*} \\
33 \mathrm{~kg} / \mathrm{Nha} / \mathrm{yr}^{*}\end{array}$ & $\begin{array}{l}15-30 \mathrm{~kg} / \mathrm{Sha} / \mathrm{yr}^{*} \\
16-24 \mathrm{~kg} / \mathrm{Nha} / \mathrm{yr}^{*}\end{array}$ & $\begin{array}{l}30 \mathrm{~kg} / \mathrm{Sha} / \mathrm{yr}^{*} \\
18-30 \mathrm{~kg} / \mathrm{Nha} / \mathrm{yr}^{*}\end{array}$ \\
\hline Critical Load** & $\begin{array}{l}\leq 0.2->2.0 \mathrm{keq} \mathrm{H}^{+} \mathrm{ha}^{-1} \mathrm{yr}^{-1} \\
\text { Typically }(0.2-0.5)\end{array}$ & $\begin{array}{l}\leq 0.2->2.0 \mathrm{keq} \mathrm{H}^{+} \mathrm{ha}^{-1} \mathrm{yr}^{-1} \\
\text { Typically }(0.2-0.5)\end{array}$ & $\begin{array}{l}\leq 0.2-2.0 \mathrm{keq} \mathrm{H}^{+} \mathrm{ha}^{-1} \mathrm{yr}^{-1} \\
\text { Typically }(\leq 0.2-0.5)\end{array}$ \\
\hline $\begin{array}{l}\text { Surface water type } \\
{ }^{*} \text { Source: Monteith an } \\
{ }^{* *} \text { Source: Hornung et }\end{array}$ & $\begin{array}{l}\text { Lochs } \\
\text { ans, } 2000 \\
1995\end{array}$ & Streams & Reservoirs \\
\hline
\end{tabular}


moorland vegetation occupies high elevation areas of the Merrick Mountains (Galloway) but elsewhere large-scale afforestation covers the landscape. A more detailed description of typical soil types, vegetation, and forestry practices in this region is given by Ferrier et al. (2001) and Helliwell et al. (2001). This pattern is similar to that found in Wales where the region is dominated by semi-natural moorland vegetation or coniferous forestry plantation at higher elevation, with improved pasture in lower valleys (Sefton and Jenkins, 1998). The Pennines differ from the other regions in that they are mostly gently undulating unimproved moorland, with improved grassland at lower elevations and commercial afforestation is rare (Evans et al., 2000).

The numbers and types of water bodies used in each region are also different. In Galloway, the surface waters of significant interest are naturally-formed, predominantly shallow upland lakes $(n=54)$. In the Pennines, the whole area has been subjected to significant engineering works to provide the water supply for the industrial cities of the northeast and so man-made reservoirs provide the key surface water bodies of interest $(n=62)$. In Wales, on the other hand, lakes are far less prevalent, the whole area is not engineered for water supply and so river systems are the main water bodies of interest, especially small first order streams $(\mathrm{n}=95)$. The model for Galloway and the Pennines, therefore, represents the entire population of lakes and reservoirs, respectively, since all were sampled for water chemistry as part of survey assessments. In Wales, it is clearly impossible to survey all rivers and so the regional model represents only a very small population of headwater streams which are assumed to represent the wider population of streams in the whole region.

\section{THE MAGIC MODEL}

MAGIC is a process-orientated model, developed to predict the long-term effects of acidic deposition on soil and surface water chemistry (Cosby et al., 1985a,b). The model consists of: (i) soil-soil solution equilibrium equations in which the chemical composition of the soil solution is assumed to be governed by simultaneous reactions involving sulphate $\left(\mathrm{SO}_{4}{ }^{2-}\right)$ adsorption, cation exchange, dissolution and speciation of inorganic and organic carbon; and (ii) mass balance equations in which fluxes of major ions to and from the soil and surface water are assumed to be governed by atmospheric inputs, mineral weathering, net uptake by biomass and loss in runoff. MAGIC produces long-term reconstructions and predictions of soil and stream water chemistry in response to scenarios of acid deposition and land use.
MAGIC uses a lumped parameter approach to: (i) aggregate the complex biological and chemical processes active at the catchment scale into a few readily described processes; and (ii) lumped catchment characteristics to represent the spatial heterogeneity of soil properties throughout a catchment. Dynamic simulation of soil and stream water chemistry is achieved by coupling the equilibrium equations with the dynamic mass balance equations for each of the major ions.

An earlier version of model (MAGIC5) lacked any process-based mechanisms for $\mathrm{N}$ retention in soil, and first order uptake coefficients were calibrated to represent catchment immobilisation such that input matched output at present day levels (Cosby et al., 1985a,b). These uptake coefficients were then assumed constant into the future. This model represents the 'best case' of $\mathrm{N}$ leakage because catchments that do not currently leak $\mathrm{N}$ will not leak as $\mathrm{N}$ deposition is reduced in the future and for those where $\mathrm{N}$ does leak, the loss will be reduced in proportion to the reduction in $\mathrm{N}$ deposition.

More recently, the model has been elaborated by Cosby et al. (2001) to incorporate $\mathrm{N}$ dynamics (MAGIC7). MAGIC7 embraces the N saturation concept (Stoddard, 1994) with the inclusion of dynamic equations for $\mathrm{N}$ cycling. The introduction of a soil organic matter compartment controls $\mathrm{NO}_{3}^{-}$leakage from the soil, based conceptually on an empirical model described by Gundersen et al. (1998). Major processes affecting $\mathrm{NO}_{3}^{-}$and $\mathrm{NH}_{4}^{+}$concentrations in surface water have been represented in the model; the most significant is nitrification (biological conversion of $\mathrm{NH}_{4}^{+}$ to $\mathrm{NO}_{3}^{-}$) and immobilisation. Nitrification is modelled as a first order process, and immobilisation of inorganic $\mathrm{N}$ into the soil organic matter is controlled by the $\mathrm{C} / \mathrm{N}$ ratio (Gundersen et al., 1998; Jenkins et al., 2001). When the C/ $\mathrm{N}$ of the soil is above an upper threshold, immobilisation of $\mathrm{N}$ in soil solution is $100 \%$ and, at low $\mathrm{C} / \mathrm{N}$ when the ratio is below a lower threshold, immobilisation becomes incomplete and $\mathrm{N}$ leaks from the soil to the surface water. The percentage of inorganic $\mathrm{N}$ immobilised is assumed to be a linear function from $100 \%$ to $0 \%$. This model represents the 'worst' case for future $\mathrm{N}$ leaching since $\mathrm{NO}_{3}^{-}$leaching will occur even with reduced inorganic $\mathrm{N}$ deposition as a result of continued input to the soil organic $\mathrm{N}$ pool.

\section{MODEL CALIBRATION}

The MAGIC calibration procedure followed is that documented by Jenkins et al. (1998) and Evans et al. (2001), and a detailed account of the calibration with $\mathrm{N}$ dynamics (MAGIC7) is given in Cosby et al. (2001) and Jenkins et al. (2001). 
The input data required by MAGIC includes annual rainfall and runoff volumes, deposition chemistry, and catchment aggregated soil physico-chemical parameters including soil depth, bulk density, cation exchange capacity, carbon pool and $\mathrm{C} / \mathrm{N}$ ratio of the organic soil compartment. The model is calibrated to surface water concentrations of calcium $\left(\mathrm{Ca}^{2+}\right)$, magnesium $\left(\mathrm{Mg}^{2+}\right)$, sodium $\left(\mathrm{Na}^{+}\right)$, and potassium $\left(\mathrm{K}^{+}\right), \mathrm{SO}_{4}{ }^{2-}, \mathrm{Cl}^{-}, \mathrm{NO}_{3-}^{-}$and $\mathrm{NH}_{4}^{+}$and soil exchangeable fractions $\mathrm{Ca}^{2+}, \mathrm{Mg}^{2+}, \mathrm{Na}^{+}, \mathrm{K}^{+}$.

Soil physico-chemical data were aggregated based upon a catchment-based weighting technique (Helliwell et al., 1998). Soil characteristics for the Galloway region were processed from the Scottish Soils Database held at the Macaulay Institute and data for the Pennines and Welsh region were derived from the England and Wales soils database held by the Soil Survey and Land Resource Centre.

Deposition data for each site in each region were derived by overlaying the catchment outline onto the UK 1999597 deposition data at a $5 \mathrm{~km} \times 5 \mathrm{~km}$ grid scale. A mean value was calculated for each catchment by averaging the values for the relevant squares and proportioning the deposition from partial squares. The UK deposition data incorporate variations in deposition resulting from orographic enhancement (Fowler et al., 1988). Rainfall volumes were obtained from the same database using the same averaging methodology. Base cation deposition was calculated from $\mathrm{Cl}^{-}$assuming no anthropogenic contribution.

The historical trend in wet deposited non-marine $\mathrm{SO}_{4}^{2-}$ was assumed to follow the sequence described by the Warren Springs Laboratory (1983), adjusted regionally to take account of observations since 1980. Other ions in deposition are assumed to remain constant throughout the simulation unless the catchment has undergone a change in land use. In the British uplands, large-scale commercial afforestation is the main land management practice. Conifer plantations significantly exacerbate the acidification status of soils and surface waters and, given that forest uptake, dry deposition and runoff are influenced by the age and forest cover at a site, historical sequences and future forecasts are constructed for the key driving variables (Harriman and Morrison, 1992). Evapotranspiration was assumed to vary between $10 \%$ for a moorland catchment to $20 \%$ for a fully forested catchment. At forested sites, runoff yield is assumed to decrease linearly with increasing area of mature canopy cover. The enhancement of acid input through dry deposition mechanisms increases deposition in forested catchments (Mayer and Ulrich, 1977). Net uptake of ions in biomass was modelled relative to the age and spatial coverage of forest within the catchment during the historical reconstruction and forecast simulation (Ferrier et al., 1995).

Surface water chemistry data from 54 sites in the Galloway region have been used in this model application. Although samples were collected in the springs of 1979, 1988, 1993, 1994, 1996, 1997 and 1998, for this model application, 'present day' chemistry was estimated as the average of data for April 1996 and April 1997. The sampling methodology and the analytical procedures are reported by Ferrier et al. (2001). The Pennine survey included a total of 62 reservoirs, all of which were sampled in April 1998. Details of the sampling and analytical methods are described by Evans et al. (2000). In Wales, in 1995, 95 headwater streams were sampled monthly for one year (Sefton and Jenkins, 1998).

The surveys in Galloway and the Pennines were considered representative of acid sensitive sites because they are above the limit of improved agricultural land, they are underlain by acid sensitive geology/soils and the majority of standing waters drain relatively small upland catchments. The chemical records from these surveys accorded well with the pattern observed in long term mean data (Evans et al., 2001), providing confidence that the single sample surveys are a reasonable representation of the longer term mean chemistry. The Pennine data were considered slightly dilute because the survey followed wet antecedent conditions and, in Galloway, high $\mathrm{NO}_{3}{ }^{-}$concentrations in the mean data from 1996/97 were attributed to a large seasonal peak in winter/ spring. The Welsh region comprises streams sampled monthly over a one year period; this higher intensity of sampling took account of the temporal variability in the stream samples. For the majority of sites in Wales, mean chemistry was considered representative of annual conditions. However, samples were collected from the highest road access point and, as a result, most catchments were large and some contained areas of improved grassland that may reduce acid sensitivity.

\section{Results}

\section{REGIONAL VARIATIONS IN CHEMISTRY}

Differences in surface water chemistry result from a range of regional and catchment specific factors including acidic and sea salt deposition, geological characteristics and land use. Similar $\mathrm{Cl}^{-}$concentrations (Table 2) suggest that the regions, although geographically located in different parts of Britain, are exposed to a similar input of sea salts presumably reflecting their location towards the western coast of the country. Median ANC and pH data show that surface waters in Galloway, the Pennines and Wales are either currently acidified or sensitive to acidification. Reservoirs in the Pennine region are the most acid of the three regions (median ANC $13 \mu \mathrm{eql}^{-1}, \mathrm{pH} 5.2$ ) and the Welsh streams are less so (median ANC $69 \mu \mathrm{eql}^{-1}, \mathrm{pH} 6.3$ ). 
Table 2. Regional surface water chemistry statistics *

\begin{tabular}{|c|c|c|c|c|c|c|c|c|c|c|c|}
\hline & & $p H$ & $A N C$ & $\mathrm{SO}_{4}{ }^{2-}$ & $\mathrm{XSO}_{4}^{2-}$ & $\mathrm{Cl}^{-}$ & $\mathrm{NO}_{3}^{-}$ & $\mathrm{NH}_{4}^{+}$ & $x \mathrm{Ca}^{2+}$ & $x M g^{2+}$ & $D O C$ \\
\hline \multirow[t]{5}{*}{ Galloway } & Minimum & 4.3 & -23 & 58 & 42 & 152 & 3 & 1 & 9 & 9 & 2 \\
\hline & $\mathrm{P}_{10}$ & 4.7 & -9 & 69 & 52 & 158 & 7 & 1 & 26 & 16 & 3 \\
\hline & Median & 5.6 & 55 & 93 & 71 & 213 & 22 & 2 & 71 & 28 & 6 \\
\hline & $\mathrm{P}_{90}$ & 6.5 & 200 & 145 & 118 & 410 & 34 & 5 & 183 & 66 & 11 \\
\hline & Maximum & 6.9 & 302 & 219 & 160 & 571 & 60 & 9 & 272 & 88 & 16 \\
\hline \multirow[t]{5}{*}{ Pennines } & Minimum & 4.0 & -152 & 121 & 107 & 132 & 16 & 1 & 18 & 7 & 1 \\
\hline & $\mathrm{P}_{10}$ & 4.1 & -85 & 164 & 144 & 175 & 26 & 1 & 39 & 24 & 3 \\
\hline & Median & 5.2 & 13 & 246 & 224 & 239 & 46 & 4 & 138 & 94 & 5 \\
\hline & $P_{90}$ & 6.6 & 108 & 355 & 317 & 472 & 77 & 9 & 243 & 157 & 8 \\
\hline & Maximum & 7.1 & 220 & 425 & 402 & 592 & 97 & 32 & 308 & 175 & 10 \\
\hline \multirow[t]{5}{*}{ Wales } & Minimum & 4.9 & -22 & 51 & 7 & 151 & 2 & 0 & 30 & 13 & 1 \\
\hline & $\mathrm{P}_{10}$ & 5.6 & -4 & 69 & 45 & 170 & 3 & 0 & 50 & 24 & 1 \\
\hline & Median & 6.3 & 69 & 107 & 84 & 225 & 12 & 0 & 98 & 51 & 2 \\
\hline & $\mathrm{P}_{90}$ & 6.9 & 309 & 196 & 164 & 337 & 47 & 0 & 290 & 107 & 4 \\
\hline & Maximum & 7.8 & 1567 & 422 & 391 & 427 & 86 & 0 & 1510 & 481 & 6 \\
\hline
\end{tabular}

${ }^{*} \mathrm{P}_{10}$ and $\mathrm{P}_{90}$ represent 10th and 90th percentiles, respectively. All concentrations are in $\mu$ eql ${ }^{-1}$ except for $\mathrm{pH}$ (log) and dissolved organic carbon (DOC $\left.\left(\mathrm{mg} \mathrm{l}^{-1}\right)\right)$. $\mathrm{XSO}_{4}{ }^{2-} \mathrm{xCa}^{2+} \mathrm{xMg}^{2+}$ is the concentration of $\mathrm{SO}_{4}{ }^{2-}, \mathrm{Ca}^{2+}$, and $\mathrm{Mg}^{2+}$ from non-marine sources. ANC, acid neutralising capacity.

Surface water chemistry in the Pennine region is dominated by high concentrations of strong acid anions, particularly $\mathrm{xSO}_{4}{ }^{2-}\left(\right.$ median $\left.=224 \mu \mathrm{eql}^{-1}\right)$ with concomitant high concentrations of $\mathrm{xCa}^{2+}$ and $\mathrm{xMg}^{2+}$ (median = $138 \mu \mathrm{eql}^{-1}$ and $94 \mu \mathrm{eql} \mathrm{l}^{-1}$, respectively). This high value for $\mathrm{XSO}_{4}{ }^{2-}$ is characteristic of the region and is significantly higher than either Galloway or Wales (median $=71 \mu \mathrm{eq}^{1^{-1}}$ and $84 \mu \mathrm{eql}^{-1}$, respectively.

The excess sulphate $\left(\mathrm{xSO}_{4}^{2-}\right)$ was determined by:

$$
\mathrm{xSO}_{4}{ }^{2-}=\mathrm{SO}_{4}{ }^{2-}-\left(\mathrm{R}^{*} \mathrm{Cl}^{-}\right)
$$

where $\mathrm{xSO}_{4}{ }^{2-}$ is the non-marine concentration of $\mathrm{SO}_{4}{ }^{2-}$, and $\mathrm{R}$ is the ratio of that ion to $\mathrm{Cl}^{-}$in seawater $\left(0.104\right.$ for $\mathrm{SO}_{4}^{2-}$ where concentrations are in $\left.\mu \mathrm{eq} \mathrm{l}^{-1}\right)$. The ratio used to calculate excess $\mathrm{Ca}^{2+}$ and $\mathrm{Mg}^{2+}$ is 0.04 and 0.198 .

Considerable inter-regional variability in nitrogen concentrations is evident (Table 2). Many surface waters in the Pennines have elevated $\mathrm{NO}_{3}{ }^{-}$concentrations in excess of $40 \mu \mathrm{eql}^{-1}$, with individual lakes reaching nearly $100 \mu \mathrm{eql}^{-1}$. Again, this contrasts with the lower median $\mathrm{NO}_{3}^{-}$ concentrations in the Galloway region and in Wales (22 $\mu \mathrm{eql}^{-1}$ and $12 \mu \mathrm{eql} \mathrm{l}^{-1}$, respectively). Minimum values for $\mathrm{NO}_{3}{ }^{-}$also differ with no site in the Pennine region having concentrations of $<10 \mu \mathrm{eql}^{-1}$ whereas, in the other regions, much lower concentrations $\left(<10 \mu \mathrm{eql}^{-1}\right)$ predominate. $\mathrm{NH}_{4}^{+}$ concentrations are zero in Wales and Galloway but, in the Pennines, some reservoirs have significant concentrations.

\section{MODELLING RESULTS}

MAGIC was calibrated successfully to a total of 201 sites (best case $\mathrm{N}$ scenario) and 161 sites (worst case $\mathrm{N}$ scenario) throughout Galloway, the Pennines and Wales. In all three regions, the simulated present day surface water ANC matches the observations closely (Fig. 1a,b,c). This implies that the difference between the sum of strong base cations $\left(\mathrm{Ca}^{2+}, \mathrm{Mg}^{2+}, \mathrm{Na}^{+}\right.$, and $\left.\mathrm{K}^{+}\right)$and strong acid anions $\left(\mathrm{Cl}^{-}, \mathrm{SO}_{4}{ }^{2-}\right.$ and $\mathrm{NO}_{3}^{-}$) corresponds to observed chemistry. Since the biological targets for recovery are described in terms of ANC, the model calibrations are acceptable.

The model indicates that surface water acidification occurred at all sites from the mid-nineteenth century to the late 1970 s, a period representing the peak of $\mathrm{S}$ deposition across the UK (Fig. 2). As a result of the increasing deposition over this period, all sites are predicted to have been acidified to some extent, but the magnitude of the ANC decline is predicted to be greater for sites in the Pennines than in Galloway and the Welsh regions. At the time of greatest deposition, simulated median ANC, was $47 \mu \mathrm{eql}^{-1}$, $-18 \mu \mathrm{eql}^{-1}, 60 \mu \mathrm{eql}^{-1}$ for Galloway, Pennines and Wales, respectively. This regional variation reflects the magnitude 

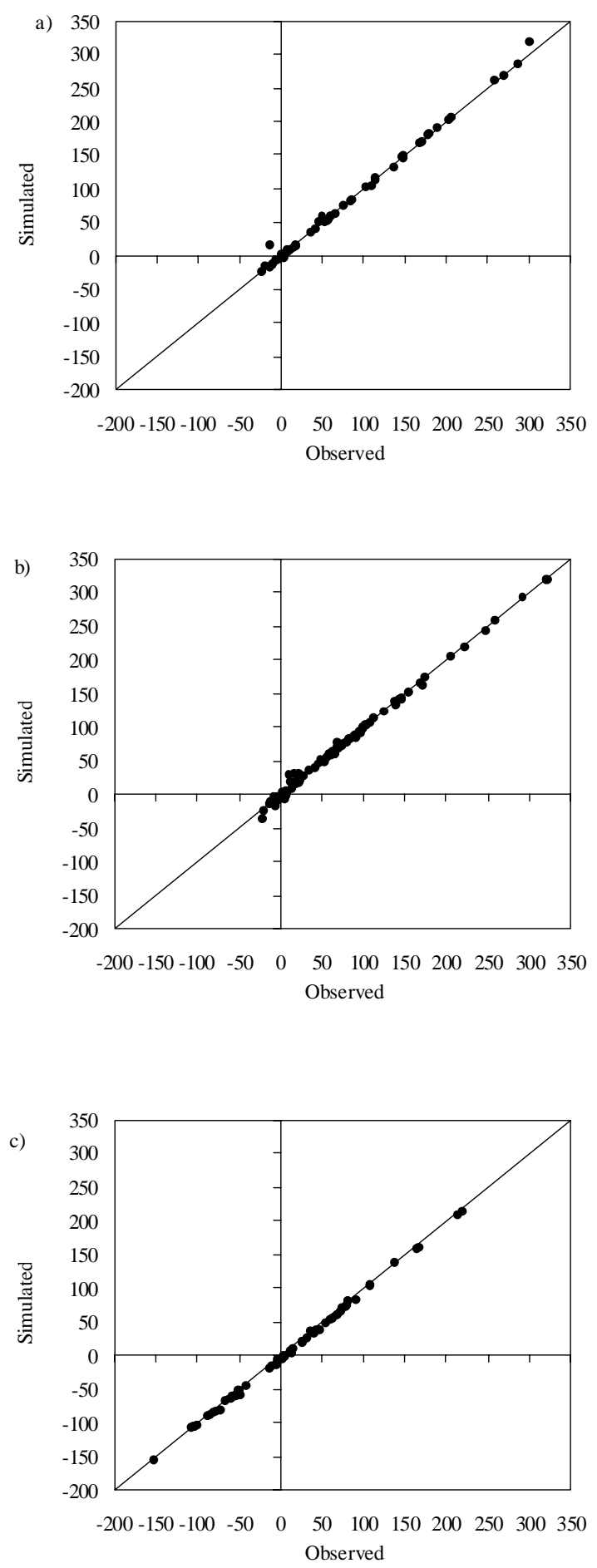

Fig. 1. Observed and simulated ANC concentrations for the regions; a) Galloway, b) Wales and c) Pennines

of S deposition which was greatest in the Pennines as a result of the proximity to significant local emission sources. In general, the largest decrease in ANC is predicted to occur at those sites with the lowest initial ANC and, hence, the biggest sensitivity to acidic inputs (Fig. 2c). Intra-regional variability in simulated ANC is most apparent in the Welsh
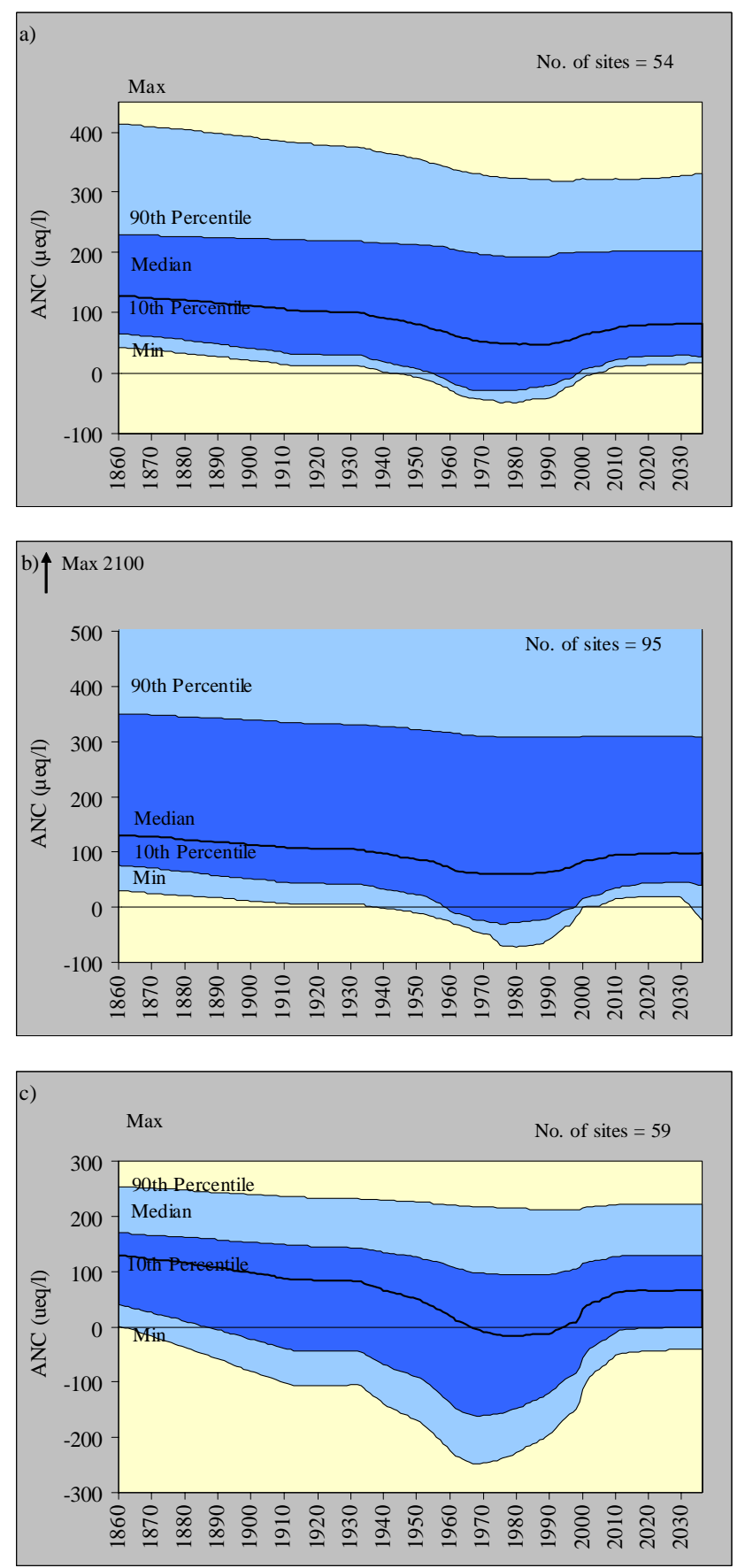

Fig. 2. Simulated trends in surface water ANC from 1860 to 2036 for; a) Galloway, b) Wales and c) Pennines (Maximum ANC concentrations, $90^{\text {th }}$ Percentile, Median, $10^{\text {th }}$ Percentile and minimum ANC concentrations)

region, where present day ANC ranges from $-21 \mu \mathrm{eql}^{-1}$ to $1567 \mu \mathrm{eq} \mathrm{l}^{-1}$ (Fig. 2b) which reflects a large variation in bedrock geology and land use. Despite differences in site characteristics in the Galloway and Pennine regions, the variability in surface water chemistry is less (Fig. 2a,c and Table 1). 
With the implementation of international protocols in the mid-1980s and the more recent Gothenburg Protocol, reductions in acidic emissions are predicted to reverse acidification processes for surface waters at most sites to 2010. Sites in the Pennine region are more responsive by future changes in deposition and are predicted to recover faster than sites in Galloway and Wales. (Fig. 2).

The results described above are based on the best-case $\mathrm{N}$ scenario (MAGIC5) where $\mathrm{N}$ inputs are calibrated to match $\mathrm{N}$ output by incorporating a constant proportional uptake factor linked to deposition to the site. MAGIC7 on the other hand (worst case scenario) allows for the potential release of nitrate if the soil $\mathrm{C} / \mathrm{N}$ declines below a specified threshold where immobilisation is considered to be less than $100 \%$. MAGIC7, therefore, simulates very different future surface water $\mathrm{NO}_{3}$ concentrations (Fig. 3a,b,c). The difference in ANC between 'best' and 'worst' cases is a result of $\mathrm{N}$ leaching (Fig. 3d,e,f). The difference between $\mathrm{NO}_{3}^{-}$leaching under the two $\mathrm{N}$ scenarios will be greater for longer term predictions beyond 2036. Assuming that $\mathrm{N}$ emission reductions are achieved in line with those agreed under the Gothenburg Protocol, $\mathrm{NO}_{3}{ }^{-}$concentrations modelled using best case scenario of $\mathrm{N}$ retention are predicted to be lower in future than those currently observed in all regions. In contrast, under the worst case scenario, $\mathrm{NO}_{3}{ }^{-}$concentrations are predicted to increase at all sites by 2036 (Fig. 3a,b,c).

Under the worst case $\mathrm{N}$ scenario, a significant increase in $\mathrm{NO}_{3}{ }^{-}$concentrations is modelled at the Pennine sites, with a regional average increase of $35 \mu \mathrm{eql} \mathrm{l}^{-1}$. Increased leaching of $\mathrm{NO}_{3}{ }^{-}$, modelled with the worst case $\mathrm{N}$ scenario, is also evident in the Welsh and Galloway regions, but the contribution of $\mathrm{NO}_{3}^{-}$to the overall acid status of surface water is less significant (mean $10 \mu \mathrm{eql}^{-1}$ and $13 \mu \mathrm{eql}^{-1}$, respectively). The Pennines currently receive significantly higher deposition of $\mathrm{N}$ than the other two regions and so signs of increasing $\mathrm{N}$ saturation are reflected in the higher surface water $\mathrm{NO}_{3}{ }^{-}$concentrations. Alternatively, the plant and soil microbial communities in the Pennines may have been significantly stressed by the high $\mathrm{S}$ deposition resulting in a lowered capability to assimilate the deposited $\mathrm{N}$.

Nevertheless, under the worst case $\mathrm{N}$ scenario, predicted $\mathrm{NO}_{3}^{-}$contribution to the total anthropogenic acid anion concentration in 2036 is still only $36 \%$ indicating that there are still significant benefits from reducing $\mathrm{S}$ inputs in terms of recovery from acidification. In Wales and Galloway, the median contributions of $\mathrm{NO}_{3}$ in 2036 are $53 \%$ and $43 \%$ respectively, indicating that further recovery from acidification is likely to require a significant decrease in $\mathrm{N}$ deposition.

The assumptions made regarding $\mathrm{N}$ leaching in the models
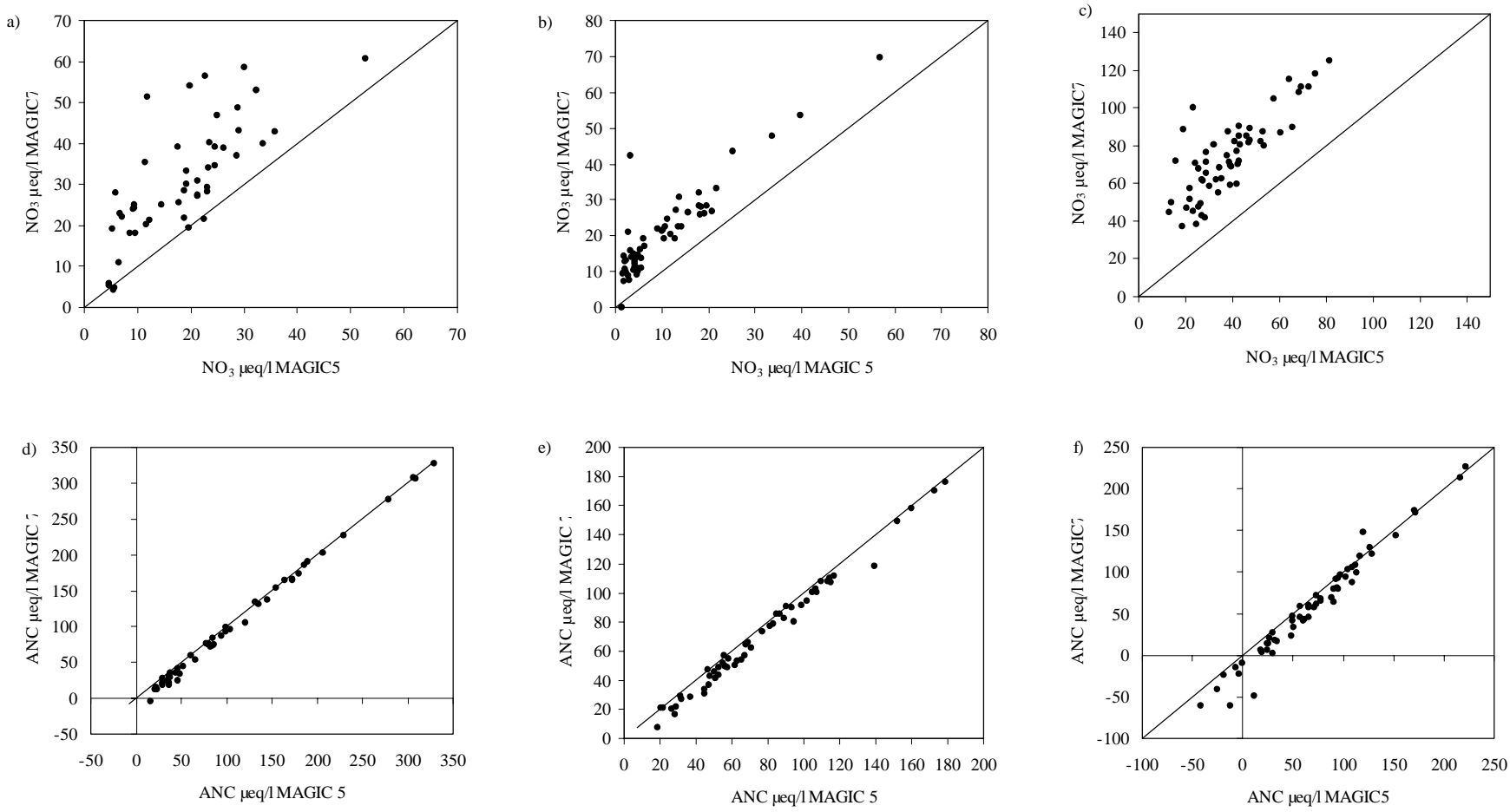

Fig. 3. Comparison of best case (MAGIC 5) and worse case (MAGIC 7) N scenario for NO and ANC concentrationsin 2036 for Galloway (a,d), Wales (b,e) and the Pennines (c,f) modelled with $S$ and $N$ reductions imposed by the Gothenburg Protocol 
and the predicted reductions in $\mathrm{S}$ and $\mathrm{N}$ deposition, promote a wide range of modelled ANC responses both within and between regions (Fig. 3d,e,f). The contribution of $\mathrm{NO}_{3}$ modelled with the worse case scenario is sufficient, marginally, to acidify surface water by lowering the ANC in 2036 by an average of $8.1 \mu^{-e^{-1}}$ for all sites included in this study. The reduction in ANC as a result of $\mathrm{N}$ leaching, will increase the number of all acid sensitive sites with ANC $<20 \mu \mathrm{eql}^{-1}$ from 12 sites under the best case $\mathrm{N}$ scenario to 25 sites under the worst case $\mathrm{N}$ scenario.

The basis for relating changes in water chemistry to effects on fish populations was established from a UK wide survey of biological and chemical records (Juggins et al., 2001; McCartney et al., 2003) and a study of 1000 Norwegian lakes (Lien et al., 1996). These studies suggested that an ANC of zero represented a $50 \%$ probability of damage to a brown trout population and an ANC of 20 reflected 95\% protection of the brown trout from damage (Lien et al., 1996). As an indication of the health of the brown trout population, therefore, it was assumed that lakes with ANC concentrations between $0-20 \mu \mathrm{eq}^{\mathrm{l}^{-1}}$ were marginal for the survival of a viable population, and those with ANC $<0 \mu$ eql ${ }^{-1}$ were unsuitable to maintain a viable population; in many cases they would be without fish. Using this categorisation, the modelled surface water quality in the midnineteenth century indicates that ANC was sufficiently high $\left(>20 \mu \mathrm{eq}^{-1}\right)$ at all sites in Galloway and Wales to support a healthy fish population (Fig. 4a). At $8 \%$ of sites in the Pennine region, however, MAGIC predicts ANC in the range 0-20 $\mu \mathrm{eql}^{-1}$. A possible cause of these low background ANC concentrations is likely to be high concentrations of organic acids or localised $\mathrm{SO}_{4}{ }^{2-}$ weathering in this acid sensitive region. Present day surface water chemistry is more acid, with conditions which are deleterious to salmonid populations throughout the UK (Fig. 4b). Model predictions to 2016, the target year for good ecological status (WFD), indicate a recovery in the predicted fish status in Galloway and Wales. Predictions of surface water ANC, modelled using both the best and worst case $\mathrm{N}$ scenarios, indicate that the ANC at $14 \%$ of the sites in the Pennine region remains $<0 \mu \mathrm{eql}^{-1}$ (Fig. $\left.4 \mathrm{c}, \mathrm{d}\right)$.

\section{Discussion and conclusions}

The implementation of the Gothenburg protocol is predicted to result in a substantial improvement in surface water ANC in all regions. Predicted trends in surface water chemistry from present day to 2036 indicate a considerable improvement in water quality with c. $37 \%, 43 \%$ and $46 \%$ recovery towards pre-acidification ANC for Galloway, the Pennines and Welsh regions, respectively ('recovery' is defined as the forecast ANC recovery to 2036 as a percent of the net ANC decline from pre-industrial conditions to present day i.e. $\left[\mathrm{ANC}_{2036}-\mathrm{ANC}_{\text {present day }}\right] /\left[\mathrm{ANC}_{\text {present day }}-\right.$ $\left.\mathrm{ANC}_{1860}\right] \times 100$ (Evans et al., 2001). The recovery in Galloway is slightly less than in the other regions as a result of the low base-status of soils at high altitude sites and extensive afforestation in lower-lying catchments. At afforested sites, second rotation forest planting is likely to slow, or in some cases prevent further recovery despite large reductions in $\mathrm{S}$ and $\mathrm{N}$ deposition. A combination of base cation uptake by the forest, enhanced deposition to the forest canopy and decreased water yield concentrating pollutants in surface waters may further contribute to the delayed recovery of ANC towards reconstructed pre-industrial conditions in the Galloway region.

With $43 \%$ of sites in the Pennines achieving background ANC concentrations in 2036, it is evident that emission reductions in this region are predicted to have had a positive impact on surface water chemistry by reducing the number of reservoirs in the most acid sensitive ANC class. Since non-marine $\mathrm{SO}_{4}^{2-}$ contributes $91 \%$ of total median $\mathrm{SO}_{4}^{2-}$ concentration in the Pennine reservoirs, the impact of large reductions in sulphur deposition is predicted to be very large; this reduction will influence, directly, the reversal of surface water acidification in this region. Furthermore, reductions in $\mathrm{N}$ deposition are unlikely to promote further surface water recovery as elevated concentrations of $\mathrm{NO}_{3}{ }^{-}$from the present day to 2036 indicate that soils may be at an advanced stage of $\mathrm{N}$ saturation.

Decades of acid deposition throughout the UK and large scale afforestation in Galloway and Wales has resulted in widespread acidification of surface waters so that $17 \%, 42 \%$ and $20 \%$ of sites in Galloway, the Pennines and Wales, respectively, are currently predicted to have an ANC concentration which is incapable of supporting a fish population (Fig. 4b). The situation will improve dramatically in 2016 in response to the emission reductions agreed under the Gothenburg Protocol.

Whilst these results are generally encouraging, improvements in surface water ANC, modelled with and without $\mathrm{N}$ dynamics, do not represent a return to preacidification status. A comparison of best case versus worst case $\mathrm{N}$ scenarios indicates that $\mathrm{N}$ leaching has a less significant impact on predicted ANC, while the reductions in $\mathrm{S}$ deposition, as predicted under the Gothenburg protocol, are more important with regard to the reversal of surface water acidification in 2036.

The EU Water Framework Directive (Directive 2000/60/ EC) aims to maintain and improve the quality of aquatic ecosystems in the EU. The results of this modelling study, therefore, have direct significance in relation to achieving 

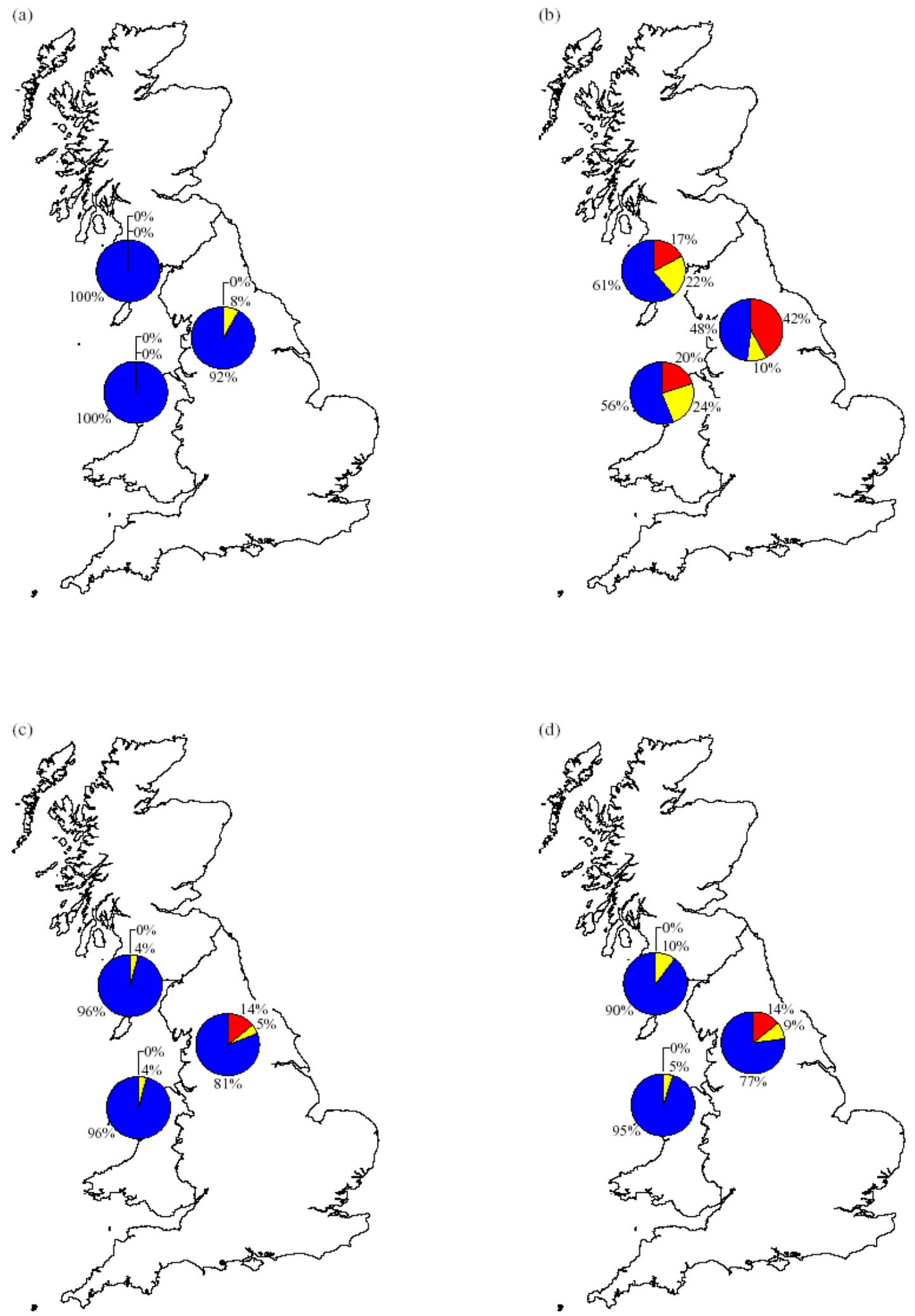

\section{$\mathrm{ANC} \mu \mathrm{eq} / \mathrm{l}$}

$\square<0 \square 0-20 \square>20$

Fig. 4. The proportion of surface water in 3 ANC categories representing the ecological status for (a) reference conditions (1860), (b) present day, (c) 2016 (best case N scenario), and (d) 2016 (worst case N scenario). 
that target. The Directive specifies that good status must represent the situation where only very minor changes to the morphology, physico-chemistry and ecology of freshwater systems have occurred. It is, therefore, important to consider whether the adoption of the Gothenburg Protocol has achieved an appropriate improvement in the chemical status of the waterbodies with respect to the potential for ecological recovery.

Predicted background ANC (Fig. 4a) indicates that chemical conditions will exist for the survival of viable fish populations in all regions, and this may be considered as achieving the necessary criteria for defining a return to 'good ecological' status as salmonids are a key indicator species. It is interesting, however, to assess the magnitude of the potential recovery against what has been modelled as 'reference' conditions for these systems (i.e. reconstructed chemistry and inferred ecology for pre-acidification conditions in 1860). In the highest ANC categories, approximately $70 \%$ of the lakes and streams will have returned to reference state but a number of waterbodies will not have met those conditions in all areas. The Directive defines reference conditions as representing those where there have been 'no, or only minor' changes as a result of human activity. This provision to accommodate minor change is key. Water bodies, therefore, do not have to be restored to their reference conditions; rather the ecological status that the water bodies must achieve is defined as a slight change from reference conditions. The standard for reference conditions must take account of an appropriate vision for good ecological status. In this instance, it is taken to relate to achieving an ANC of $>20 \mu \mathrm{eql}^{-1}$. It is clear that any remedial management in restoring waters in UK regions should focus on those waterbodies presently between 0 and $20 \mu \mathrm{eql}^{-1}$ in Galloway (five sites) and Wales (three sites) and the group of lakes with ANC less that $0 \mu \mathrm{eql}^{-1}$ in the Pennines (eight sites). The question of what level of deviation of ANC away from the reconstructed reference condition is allowable under a reference condition remains to be quantified. Furthermore, this paper reports the timescale of chemical recovery and does not consider the time lags that may well occur in terms of biological recovery (Wright and Lie, 2002). As such, the results presented represent a best case with respect to predicted fish status.

\section{Acknowledgements}

This work was supported financially in part by the Commission of the European Communities RECOVER:2010 project (EVK1-CT-1999-00018), the Scottish Executive Environment and Rural Affairs Department, the Department of the Environment, Food and
Rural Affairs (Contract No. EPG 1/3/194) and the UK Natural Environment Research Council. Thanks are due to the wide community of researchers throughout the UK who have assisted in sample collection in general and analysis in particular, to Beate Gannon at the Centre for Ecology and Hydrology, Wallingford and to Malcolm Coull and Keith Mathews at the Macaulay Institute for providing GIS support and creating maps. The authors are also grateful to David Fowler, Jane Hall, Sarah Metcalfe and Duncan Whyatt for contributing deposition data. The support of laboratory staff at $\mathrm{CEH}$ Wallingford and the Macaulay Institute is also acknowledged.

\section{References}

Batterbee, R.W., Anderson, N.J., Appelby, P.G., Flower, R.J., Fritz, S.C., Haworth, E.Y., Higgitt, S., Jones, V.J., Munroes, M.A.R., Natkanski, J., Oldfield, F., Patrick, S.T., Richardson, N.G., Rippey, B. and Stevenson, A.C., 1988. Lake acidification in the UK 1800-1986: evidence from the analysis of lake sediments. ENSIS Publishing, London, UK.

Cosby, B.J., Wright, R.F., Hornberger, G.M. and Galloway, J.N., 1985a. Modelling the effects of acid deposition: assessment of a lumped parameter model of soil water and streamwater chemistry. Water Res., 21, 51-63.

Cosby, B.J., Wright, R.F., Hornberger, G.M. and Galloway, J.N., 1985b. Modelling the effects of acid deposition: Estimation of long term water quality responses in a small forested catchment. Water Resour. Res., 21, 1591-1601.

Cosby, B.J., Ferrier, R.C., Jenkins, A. and Wright, R.F., 2001. Modelling the effects of acid deposition: refinements, adjustments and inclusion of nitrogen dynamics in the MAGIC model. Hydrol. Earth Syst. Sci., 5, 499-517.

Evans, C.D., Jenkins, A. and Wright, R.C., 2000. Surface water acidification in the South Pennines I. Current status and spatial variability. Environ. Pollut., 109, 11-20.

Evans, C., Jenkins, A., Helliwell, R., Ferrier, R. and Collins, R., 2001. Freshwater acidification and recovery in the United Kingdom. Centre for Ecology and Hydrology report. ISBN 1 903741017.

Ferrier, R.C., Wright, R.F., Cosby, B.J. and Jenkins, A., 1995. Application of the MAGIC model to the Norway spruce stand at Solling, Germany. Ecol. Model., 83, 77-84.

Ferrier, R.C., Helliwell, R.C., Cosby, B.J., Jenkins, A. and Wright, R.F., 2001. Recovery from acidification of lochs in Galloway, south-west Scotland, UK:1979-1998. Hydrol. Earth Syst. Sci., 5, 421-431.

Findlay, D.L., 2003. Response of phytoplankton communities to acidification and recovery in Killarney Park and the experimental lakes area, Ontario. Ambio, 32, 190-195.

Fowler, D., Cape, J.N., Leith, I.D., Chourlton, T.W., Gay, M.J. and Jones, A., 1988. The influence of altitude on rainfall deposition at Great Dun Fell. Atmos. Environ., 22, 1355-1362.

Gundersen, P., Emmett, B.A., Kjønaas, O.J., Koopmans, C.J. and Tietema, A., 1998. Impact of nitrogen deposition on nitrogen cycling in forests: a synthesis of NITREX data. Forest Ecol. Manage., 101, 37-55.

Harriman, R. and Morrison, B.R.S., 1992. Ecology of streams draining forested and non-forested catchments in an area of central Scotland subject to acid deposition. Hydrobiologia, $\mathbf{8 8}$, 251-263. 
Helliwell, R.C., Ferrier, R.C., Evans, C. and Jenkins, A., 1998. A comparison of methods for estimating soil characteristics in regional acidification models; an application of the MAGIC model to Scotland. Hydrol. Earth Syst. Sci, 2, 509-520.

Helliwell, R.C., Ferrier, R.C., Johnston, L., Goodwin, J. and Doughty, R., 2001. Land use influences on acidification and recovery of freshwaters in Galloway, south-west Scotland. Hydrol. Earth Syst. Sci., 5, 451-458.

Hornung, M., Bull, K.R., Cresser, M., Ullyett. J., Hall, J.R., Langan, S.J., Loveland, P.J. and Wilson, J., 1995. The sensitivity of surface waters of Great Britain to acidification. Environ. Pollut., 87, 204-317.

Jenkins, A., Helliwell, R.C., Swingewood, P.J., Sefton, C., Renshaw, M. and Ferrier, R.C., 1998. Will reduced sulphur emissions under the Second Sulphur Protocol lead to recovery of acid sensitive sites in the UK? Environ. Pollut., 99, 309318.

Jenkins, A., Ferrier, R.C. and Helliwell, R.C., 2001. Modelling nitrogen dynamics at Lochnagar, N.E.Scotland. Hydrol. Earth Syst. Sci., 5, 519-527.

Juggins, S., 2001. The CLAM biological-chemical database: the development and application of biological models to predict taxon distributions from SSWC and MAGIC hydrochemical models. In: summary of research under DETR Contract Acidification of freshwaters: the role of nitrogen and the prospects for recovery, C. Curtis and G. Simpson, (Eds.) 123146. ECRC Research Report No. 79. Environmental Change Research Centre, University College London, UK. EPG1/3/117.

Lien, L., Raddum, G.G., Fjellheim, A. and Henrikesen, A., 1996. A critical limit for acid neutralizing capacity in Norwegian surface waters, based on new analyses of fish and invertebrate responses. Sci. Total Environ., 177, 173-193.

Mayer, R. and Ulrich, B., 1977. Acidity of precipitation as influenced by the filtering of atmospheric $\mathrm{S}$ and $\mathrm{N}$ compoundsits role in the element balance and effect on soil. Water Air Soil Pollut., 7, 409-416.

McCartney, A.G., Harriman, R., Watt, A.W., Moore, D.W., Taylor, E.M., Collen, P. and Keay, E.J., 2003. Long-term trends in pH, aluminium and dissolved organic carbon in Scottish fresh waters; implications for brown trout (Salmo trutta) survival. Sci. Total Environ., 310, 133-141.
Monteith, D.T. and Evans, C.D. (Eds.), 2000. The UK Acid Waters Monitoring Network: 10-Year Report. Analysis and Interpretation of Results, April 1988-March 1998. ENSIS Publishing, London.

NEGTAP, 2001. Transboundary Air Pollution: Acidification, Eutrophication and Ground Level Ozone in the UK. DEFRA. Contract EPG 1/3/153. ISBN 1870393619.

Nilsson, J. and Grennfelt, P., 1988. Critical loads for $S$ and $N$. Nordic Council of Ministers, Copenhagen, Denmark.

Ormerod, S.J. and Tyler, S.J., 1989. Long-term change in the suitability of Welsh streams for dippers (Cinclus-cinclus) as a result of acidification and recovery - a modeling study. Environ. Pollut., 62, 171-182.

Raddum, G.G. and Fjellheim, A., 2003. Liming of River Audna, Southern Norway: A large scale experiment of benthic invertebrate recovery. Ambio, 32, 230-234.

Raddum, G.G. and Skjelkvale, B.L., 2001. Critical limit of acidifying compounds to invertebrates in different regions of Europe. Water Air Soil Pollut., 130, 825-830.

RGAR, 1997. Acid Deposition in the United Kingdom 1992-94. Fourth Report of the Review Group on Acid Rain. AEA Technology, Culham, UK.

Sefton, C.E.M. and Jenkins, A., 1998. A regional application of the MAGIC model in Wales: calibration and assessment of future recovery using a Monte-Carlo approach. Hydrol. Earth Syst. Sci. 2, 521-531.

Stoddard, J.L., 1994. Long-term changes in watershed retention of nitrogen: Its causes and aquatic consequences. In: Environmental chemistry of lakes and reservoirs, L. Baker (Ed.), Advances in Chemistry Series No. 237, American Chemical Society, Washington, D.C. 223-284.

Warren Springs Laboratory, 1983. Acid deposition in the United Kingdom. Warren Springs Laboratory, Stevenage.

Wright, R.F. and Lie, M.C., 2002. Workshop on models for biological recovery from acidification in a changing climate, 9-11 September 2002, Grimstad, Norway. LNR 4589-2002. 